\title{
Docuweb: pautas y metodología para la creación de un nuevo género periodístico
}

\author{
Docuweb: kazetaritza-genero berria sortzeko \\ jarraibideak eta metodologia
}

\section{Docuweb: guidelines and methodology for the creation of a new journalistic genre}

\section{Santiago Martínez Arias ${ }^{1}$ Rafael Díaz Arias ${ }^{2}$}

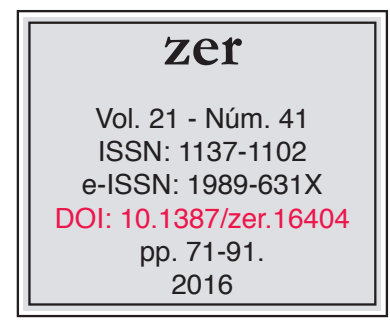

Recibido el 8 de enero de 2016, aceptado el 3 de mayo de 2016.

\section{Resumen}

Análisis de la adaptación del reportaje y el documental a la multimedialidad e interactividad que ofrece internet. Se desarrolla una metodología básica para su categorización y creación. El caso de estudio es el documental web "Honduras: en el reino del plomo". Mediante encuestas y grupos de discusión, se indaga sobre su efectividad narrativa y satisfacción para el espectador. Tanto desde el punto de vista clasificatorio, como desde el punto de vista de la producción, lo esencial es discernir las funciones narrativas, comprobando que la satisfacción, en el caso estudiado, de los espectadores/receptores es limitada.

Palabras Clave: Géneros, documental, tecnología, entretenimiento, información, formatos.

\section{Laburpena}

Erreportajea eta dokumentala internetek ematen dituen multimediarako eta elkarreragiteko aukeretara nola egokitzen diren aztertzea. Oinarrizko metodologia bat garatu da, generoa kategorizatzeko eta sortzeko. "Honduras: en el reino del plomo" web dokumentala da aztergaia, eta inkesten eta eztabaida-taldeen bitartez aztertu da ea dokumentalaren narrazioa eraginkorra den eta ea ikuslea asetzen duen. Hala sailkapenaren ikuspegitik nola ekoizpenaren ikuspegitik, garrantzitsuena narrazio-funtzioak bereiztea da. Horren bidez egiaztatu da ikusle/hartzailearen asetze-maila mugatua dela aztertutako kasuan.

\footnotetext{
Universidad Complutense de Madrid, samartin@ucm.es

2 Universidad Complutense de Madrid,diaz.r@ccinf.ucm.es
} 
Gako-hitzak: Generoak, dokumentala, teknologia, entretenimendua, informazioa, formatuak.

\begin{abstract}
This paper studies the adaptation of audiovisual genres of reportage and documentary to multimedia and interactivity of the Internet. A basic methodology for building and categorizing products is developed. We compare traditional and interactive versions on our case of study and through surveys and focus groups, exploring the narrative effectiveness and satisfaction for the viewer. One conclusion is that for categorizing and producing, it is essential to discern the narrative functions of these products. And, as second finding, satisfaction of viewers / receivers is limited, although the validity of this conclusion cannot be generalized beyond the case study.
\end{abstract}

Keywords: Genres, documentary, technology, entertainment, information, formats. 


\section{Introducción}

El documental web (docuweb o documental interactivo) ha alcanzado un notable grado de desarrollo, si bien todavía no tanto como el documental audiovisual convencional (León y Negredo, 2014). El documental web tiene diversas posibilidades de acceso y estructuración, y la potencia de ampliar contenidos (enlaces externos, producciones secundarias y versiones complementarias). Es una forma mucho más flexible de presentar contenidos estructurados en capas, que facilitan el acceso y la selección por parte del público. Incluso el espectador puede erigirse en cogenerador de contenidos, constituyendo así en una forma más de la cultura participativa (Jenkins, 2008). Su producción se adapta ahora a nuevas plataformas: móviles, tabletas, televisión conectada.

Uno de los mayores atractivos de estos productos es la relación de interdependencia creada entre el usuario y la realidad de la que informan o representan (Aston y Gaudenzi, 2012). La respuesta del receptor, que no es posible en una narrativa lineal, ofrece la oportunidad, tanto a los participantes como a los creadores, de redefinir y cambiar el estatus de los géneros periodísticos.

En ciberperiodismo los géneros clásicos se adaptan a las nuevas estructuras tecnológicas y comunicacionales "al evidenciar convenciones narrativas asimilables en sus fines y funciones" (Larrondo, 2010: 164). Y los resultados no son siempre fácilmente clasificables atendiendo a las viejas categorías.

Hablar de "documental web" (de aquí en adelante docuweb) como nuevo género periodístico supone hablar primero del vídeo y su presencia en internet. El vídeo es el contenido con más rápido crecimiento en la red: entre 2010 y 2015 su tráfico se ha multiplicado por tres y se estima que entre 2005 y 2020 lo haga por cien (Cisco 2016). Ello está en relación directa con nuevas fórmulas de grabación y edición que hacen, además, que algunos de los contenidos más vistos en la red sean precisamente los que elaboran los propios usuarios.

El otro polo a tener en cuenta en esta categorización es la interactividad, que rompe la linealidad del documental clásico y aporta al internauta la capacidad de seleccionar contenidos, dialogar y participar en el proceso, adoptando determinados papeles e incluso aportando sus propios contenidos. Todo ello redunda en un mayor atractivo de estos productos, al menos (se presupone) para las audiencias más jóvenes.

\section{Orígenes y concepto}

En televisión nos hemos de remontar hasta los años setenta para obtener noticia de los primeros experimentos de interactividad, que no pasaron de prototipos. Hasta la aparición de la web, la interacción se desarrolla principalmente a través de soportes externos y en los campos de los juegos y los productos didácticos. "Aspen Movie Map" y "Sim City" son los dos primeros precedentes del documental interactivo previo a internet (Gifreu, 2013: 52). Después, la interactividad que permite la web ha sido explorada para crear nuevas narraciones por cibermedios y productoras audiovisuales. Los MediaLab han creado productos entre el especial informativo y el documental web, pero en este terreno destacan dos instituciones ya punteras en la 
producción de documentales clásicos, el National Film Board de Canadá y el canal francobritánico Arte. Entre los canales de televisión destaca la BBC, con su esfuerzo por dotar de interactividad a productos como The Life Of Mammals, The Virtual Revolution en la plataforma de televisión conectada o híbrida red Button (Botón Rojo también para TVE). En cualquier caso, la web 2.0 nos ha enseñado a convertir un documental interactivo en un producto participativo (Gifreu, 2013: 98).

Pese a los procesos de convergencia e hibridación, estos productos mantienen diferencias dependiendo de su medio de origen (prensa, televisión, cibermedio nativo), y de ahí precisamente la dificultad de establecer una guía de referencia o unas normas de estilo a la hora de la creación de este nuevo género. Bock (2015) ha constatado en Estados Unidos cómo los vídeos en cibermedios cuya matriz es una televisión mantienen el estilo diegético de las noticias de los informativos, con el reportero adoptando el papel del narrador; en cambio, los vídeos de ciberdiarios, sin esa tradición narrativa detrás, son más miméticos, muestran (por ejemplo con grabaciones sin editar) más que cuentan, sin un periodista narrador. Esta tendencia no se reproduce tan claramente en España, pues sólo aproximadamente un tercio de los vídeos de los ciberdiarios son de producción propia, siendo el resto noticias de agencia, realizadas con el estilo de los informativos de televisión (Mayoral y Edo, 2014: 250).

Podemos llamar, de esta forma, docuweb a las adaptaciones del género informativo proveniente de los medios audiovisuales. Frente a éste, todo lo que proviene de los medios escritos se podría encajar en primera instancia en el género del reportaje multimedia. No obstante, en el docuweb están presentes características del reportaje tradicional, como son su carácter interpretativo, su virtudes expresivas y su carácter híbrido (Marreno, 2008). Ambos se solapan en ocasiones, se cruzan y se mezclan y en definitiva todos ellos se disputan al receptor, a la audiencia y el espacio en la red desde una estructura abierta, característica desde sus inicios del reportaje como género hipertextual (López García, 2003: 460).

Podríamos estar alejándonos del reportaje, más utilizado como denominación de una adaptación de género para los medios impresos, frente al documental más utilizado en el terreno audiovisual, sin embargo nuestra clasificación contempla este género como una de las partes del todo que conforma el docuweb. Aunque los dos coinciden en su fondo, el reportaje tiene como específico contar historias y mostrar situaciones que ejemplifican un asunto periodístico. El documental audiovisual siempre ha tenido una vinculación más laxa con la actualidad más inmediata e incluso la capacidad de convertir un asunto concreto de actualidad en un tema global y atemporal (Fernandez Jara y Roel, 2014), superando su caducidad y centrándose en lo perdurable (Marta, 2012: 97). En ambos encontramos una unidad narrativa con estructura general de planteamiento, nudo y desenlace, y punto de vista unificador. En un medio impreso utilizamos los bloques gráficos con los recursos habituales de tipografía, titulares, imágenes, conjuntos gráficos, recuadros y elementos tipográficos distintos de la letra, para estructurar un reportaje. Esa idea principal se ve enriquecida con ese tipo de recursos, que en el documental se corresponde con las estructuras narrativas diversas: bloques temáticos, historias personales, estructura cronológica, un proceso, un viaje o un espacio.

Documentar lo real y hacerlo a través de internet (Aston y Gaudenzi, 2012) no es una definición suficiente para nuestro género, que requiere otros elementos 
diferenciadores. Así, Aston y Gaudenzi establecen finalmente una taxonomía propia del documental interactivo: conversacional, hipertextual, participativo y experiencial. Esta descripción corresponde al desarrollo o evolución conceptual del documental web, en orden a plantear una primera discusión sobre el género de lo que ellas denominan "i-docs".

Estas autoras indagan en la definición y aunque su primera idea es muy básica nos sirve también para establecer una primera referencia académica: "Cualquier proyecto que comienza con la intención de documentar lo 'real' y que utilice tecnología digital interactiva para realizarlo puede ser considerado como documental interactivo" (Aston y Gaudenzi, 2012: 125) ${ }^{3}$. Normalmente un docuweb está basado en la hipertextualidad, sin desaprovechar otros rasgos característicos del hipertexto, como la participación y conversación con el internauta, que a esta alturas ha desarrollado capacidades cognitivas avanzadas a partir de planteamientos deductivos e inductivos (Díaz Noci, 2009: 218) y, por supuesto, otro rasgo proveniente de la imagen, la experiencia inmersiva. Es decir, se diseñan "experiencias conceptualmente unificadas" (O’Flynn, 2012).

\section{Estado de la cuestión}

Las televisiones públicas europeas están haciendo una labor intensa en el desarrollo de este nuevo género. RTVE ha mostrado gran interés y esfuerzo a la hora de poner en marcha proyectos de adaptación de sus documentales a las nuevas tecnologías, en su Lab RTVE, con extensiones web para los documentales de sus programas informativos más habituales (Crónicas, En Portada, Documentos TV) y otros específicos sin origen en un programa.

El abanico de posibilidades es casi inabarcable, ya que cada equipo profesional propone su estructura y su estilo. De ahí la necesidad de elaborar una metodología unívoca para la creación de piezas de este género. Esta variedad la podemos comprobar en los ejemplos elegidos por Domínguez (2010) para seleccionar formas distintas de elaboración de documentales para web, con la serialización dosificada, el contacto con los entrevistados, las encuestas puntuales y la integración de las redes sociales (Prison Valley de Arte). Otro ejemplo es la utilización de los recursos de ocularización en primera y segunda personal gramatical, en Journey to the End of Cool (Honkytonk Films). O la escena esférica hecha a partir de un curioso montaje fotográfico con momentos domésticos y vistas del lugar, en Out of my Window (de Katerina Cizek para el proyecto Highrise). Vemos así una variedad de estilos en diversas propuestas y realizaciones a lo largo y ancho de la red, que exige la clasificación de todo ese material.

Siguiendo a Gifreu, podemos establecer los puntos en común entre el documental audiovisual y el docuweb. El autor habla de líneas de confluencia para la creación de un nuevo género periodístico, y aunque el docuweb surge con un importante apoyo audiovisual encuentra un desarrollo particular en la capacidad multimedia que le ofrecen las nuevas modalidades de navegación e interacción. Es un género "fruto de una doble hibridación: entre audiovisual -género documental-e interacción -medio digital interactivo-, y entre información -contenidos- y entretenimiento -interfaz

Traducción propia. 
navegable-" (Gifreu 2011). Es necesario, por tanto, una vez reconstruida su historia establecer las bases sobre las que se crea el género.

El documental nace del reportaje y tiene su mayor expresión en el audiovisual. Un documental no es un reportaje, al igual que un docuweb no es un documental, sin embargo podemos establecer concomitancias razonables entre el reportaje -incluso en su versión impresa en papel-con el docuweb. La gestión de la realidad documentada estaba en manos del autor o director del documental, y ahora en el interactivo pasa a manos del espectador mediante las opciones en la elección y el control de la linealidad. Se abre la realidad a múltiples visiones o ángulos, concretada en las cuatro características básicas de la interacción: la capacidad de observación, de exploración, de modificación y la reciprocidad (Meadows, 2003). El espectador está dentro del discurso documental pudiendo elaborarlo de forma única. En este sentido, la interactividad enlaza con la naturaleza mimética del documental audiovisual clásico, que muestra, dejando más libertad para construir el relato al espectador que en el caso del reportaje (escrito o audiovisual), de naturaleza diegética, en la que el periodista cuenta y construye un relato mucho más cerrado (Bock 2015: 4).

\section{Categorización de productos}

\subsection{Recursos}

Cabe intentar una taxonomía en función de los recursos empleados. Los docuwebs plantean, amplían y profundizan e invitar a explorar y jugar (León y Negredo, 2013). El primero recurso se refiere a la secuencia de presentación, tras la cual aparecerá el índice o pantalla de navegación que muestra la estructura del documental, sea cronológica, geográfica, temática o personal. En ocasiones se presenta un mapa como modo principal de acceso, independientemente de que se trate de un reportaje multimedia, docuweb o vídeo. El segundo recurso utilizado en los documentales sería el de los espacios físicos virtuales en los que aparecen objetos que darán entrada a los diversos desarrolos o elementos componentes de la pieza. De esta forma se invita al espectador a participar y explorar las posibilidades de forma personal. Por último tenemos los docuweb que sugieren una experiencia interactiva e inmersiva, con diversas posibilidades más cercanas a la estructura de vídeojuego de rol, sin dejar de lado la información como eje estructural.

En todos ellos se fusionan distintos lenguajes, pero la narrativa no se expande a través de distintas plataformas de forma fragmentaria, como ocurre en las narrativas hipermedias (Scolari, 2009: 587; Gosciola y Campalans, 2013: 46), sino que se desarrolla en una única plataforma. Es una obra abierta, pero obra única.

\subsection{Teorías y clasificación}

¿Qué es lo que predetermina el formato multimedia para un documental? En la taxonomía aquí elaborada podemos inferir varias formas de condicionamiento. Nos preguntamos si la propia información condiciona el formato o si podemos adaptar un formato preseleccionado a cualquier tipo de información. Depende de ambos: del tipo de información que queramos comunicar y de la información y la fuente de la 
que participemos. Así, a mayor unidad narrativa, más cerca estamos del reportaje. A mayor dispersión narrativa, entramos en el terreno del especial.

El origen del tipo de medio, o productor, determina el uso de los elementos expresivos o media. Si el productor es un periódico, predomina el texto. Si es una televisión o un productor de documentales, será el vídeo. En los especiales, en cuanto que recopilatorios que son, las piezas de información están casi siempre elaboradas en un único lenguaje: piezas de texto, galerías fotográficas, vídeos o audios. En cambio, en los reportajes y documentales, aparecen dos polos entre los que se sitúan los distintos productos: predominio del texto o predominio del vídeo. Cuando el texto es el protagonista se convierte en una guía de lectura lineal de la que se van colgando el resto de elementos expresivos multimedia, que apoyan o complementan el relato textual. En cambio, cuando el vídeo es protagonista el relato se completa con informaciones en texto, pero con un papel subordinado, porque todos los bloques narrativos navegables son vídeos.

En su estado actual, estos productos se caracterizan más por su poder visual y la integración de medios expresivos que contrasta con una interactividad participativa limitada (Vázquez Herrero y López García, 2015). La interactividad dialógica suele reducirse a los comentarios sobre el tema. Sólo en contados casos existe una interactividad participativa -pidiendo que adoptemos el papel de reportero o participando en una especie de juego inmersivo-. La interactividad participativa es el mejor presupuesto de la interactividad dialógica: participamos en el debate desde el conocimiento que nos ha dado el compromiso con el problema.

Vista la literatura y los ejemplos escogidos podemos elaborar una clasificación en la que utilizaremos la estructura de la pieza o piezas periodísticas como criterio de selección para encajarlos en un determinado formato dentro del docuweb. Así podemos establecer los siguientes subgéneros del docuweb:

a) Especiales (con especial informativo, especial interactivo y especial hemerográfico).

b) Reportaje multimedia.

c) Documental audiovisual interactivo.

\subsubsection{Especiales informativos}

Entre los especiales, una primera categoría es el "especial informativo", que Larrondo (2011: 75) considera el ejemplo por excelencia del reportaje hipermedia. Con una navegación sencilla se ofrece la reencarnación multimedia en gran formato del informe. Se estructura en capas narrativas, pero estas capas no son narraciones cerradas, sino recopilación de información que responde a un determinado criterio, perspectiva o punto de vista. En él puede haber historias y hasta piezas informativas que sean reportajes, pero carece de la concentración narrativa del reportaje en sentido estricto. La confusión en la clasificación viene de que muchas veces los productores denominan a estos especiales 'reportajes multimedia', 'docuweb' o 'documental interactivo'. Los más sencillos se limitan a recopilar información en 
bloques temáticos a los que se accede a través de una barra de navegación, como en el seleccionado para este estudio sobre el "Caso Malaya", del diario $A B C$ en su versión electrónica.

Otros desarrollan bloques narrativos a los que se accede desde elementos gráficos como fotografías, galerías fotográficas u otros. Es el caso del especial del diario $E l$ País sobre los "Premios Goya".

En otros casos los especiales se alimentan no sólo de contenidos producidos para la ocasión, sino también de noticias de actualidad etiquetadas convenientemente. Ocurre en "Elecciones Generales" de El Mundo y "Lotería" de RTVE. En estos ejemplos se evidencia la voluntad de abarcar la mayor cantidad posible, estructurada temáticamente, pero sin un hilo narrativo común. Un reportaje -multimedia o no- se concentra en mostrar un aspecto significativo de la realidad, no en abarcar las múltiples perspectivas de una gran cuestión periodística.

Figura 1. Reportajes multimedia en diversos medios (ABC, El País, El Mundo, RTVE).

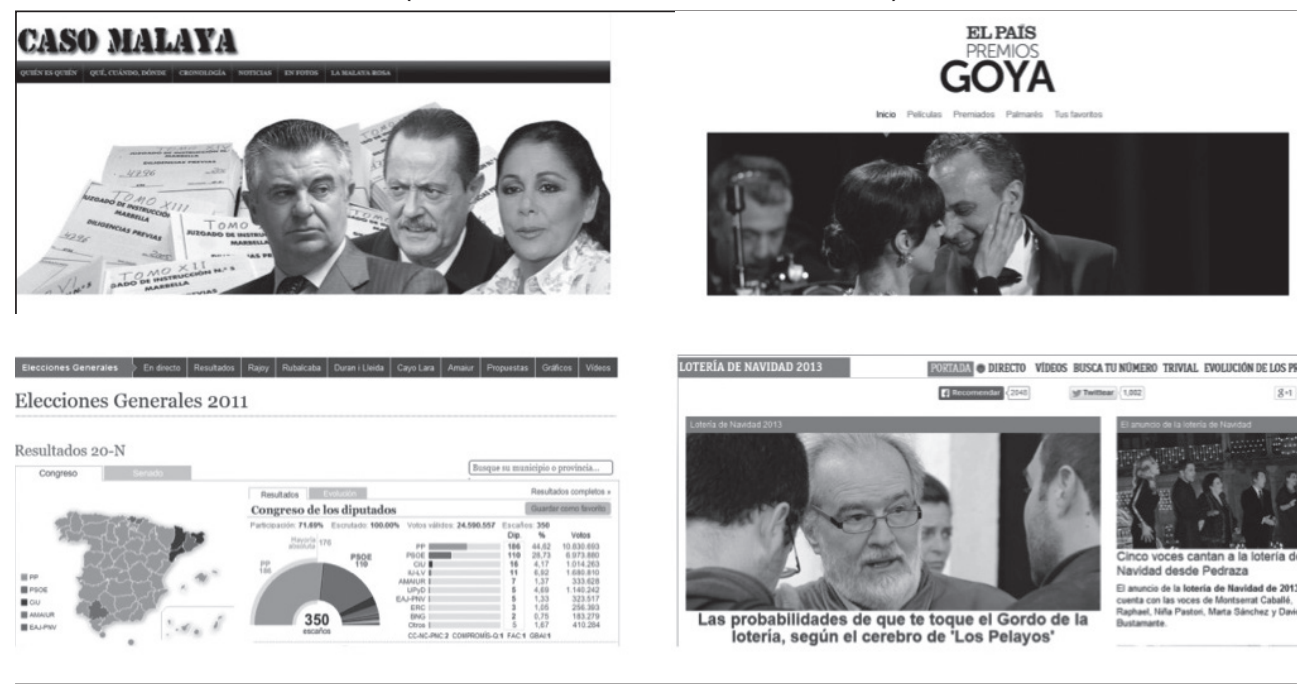

\subsubsection{Especial hemerográfico y especial interactivo}

Entre los contenidos ofrecidos por The Economist con ocasión de la muerte de Nelson Mandela se encuentra un trabajo multimedia, que parece un reportaje, pero en realidad no es más que un especial hemerográfico. Desde el semanario se accede a un sitio específico, con un vídeo inmersivo en el que se muestra a personas de razas, edades y estatus distintos, representantes de esa Sudáfrica "arcoíris" que quiso Mandela, realizando un tributo con pequeños objetos, bajo el lema "A lo largo de una larga vida, un hombre va aprendiendo quien es". La estructura narrativa nos lleva a un recorrido sobre momentos decisivos para terminar nuestra navegación en la hemeroteca del semanario. Tiene logros importantes: encadenar un vídeo con una página de navegación y, sobre todo, que la estructura narrativa/página de navegación sea un espacio simbólico. 
Otro ejemplo, que podríamos denominar especial informativo interactivo es el realizado por el LAB de RTVE con ocasión de la muerte del estadista sudafricano. La barra superior recopila temáticamente informaciones diversas elaboradas por TVE y un enlace al programa especial de la televisión pública. En el centro de la página se da acceso a un reportaje de 6 minutos elaborado previamente a la muerte del líder, y un texto multimedia "El siglo de Mandela", un texto lineal en el que se incrustan elementos multimedia. El más importante, una cronología o línea de tiempo por la que podemos recorrer el siglo de Mandela. El texto va apoyado por gráficos interactivos e incorpora linealmente los bloques temáticos a los que también se puede acceder desde la barra de navegación. El producto no es un reportaje, pues carece de un punto de vista específico y de un hilo narrativo. Es un especial que pretende recopilar y ordenar dentro de una navegación hipermedia contenidos multimedia de distinto origen (línea de tiempo; gráficos interactivos que apoyan el texto o los vídeos emitidos por la cadena). La interacción se limita a los gráficos y a la posibilidad de compartir este producto en las redes sociales.

Figura 2. Especiales "hemerográficos" en The Economist y RTVE.

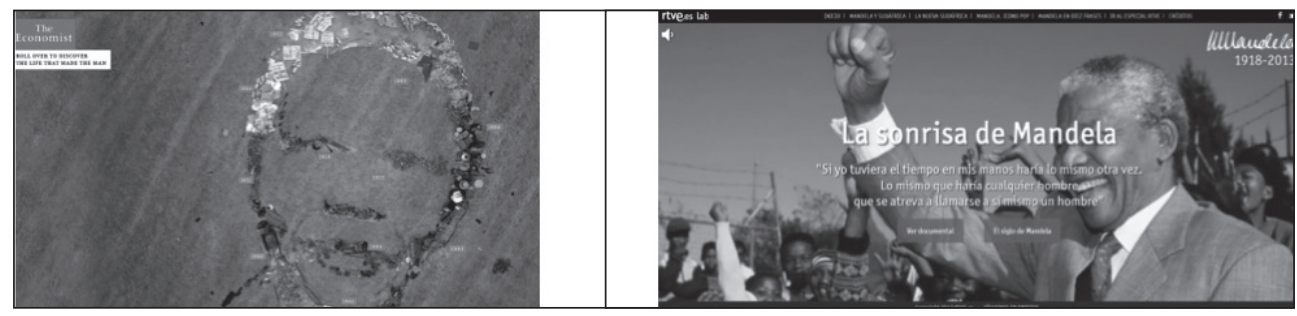

1. Especial hemerográfico The Economist "The Long Walk of Mandela”.

2. Especial de RTVE “La sonrisa de Mandela”.

\subsubsection{Reportajes multimedia}

En el reportaje multimedia se utilizan distintos elementos expresivos dentro de cada pieza, capa o bloque narrativo. Lo importante es que cada uno de estos elementos expresivos se use del modo más eficaz posible. Por ejemplo, una foto puede ser una buena condensación expresiva que resuma una historia o situación, un gráfico puede contextualizar la historia o situación concreta y un vídeo trasladar al receptor la experiencia de una entrevista completa.

Un reportaje multimedia, como cualquier reportaje, tiene que tener una estructura y un punto de vista unificador. Los reportajes de prensa, radio o televisión son lineales. El reportaje multimedia puede descomponer su estructura en capas y bloques narrativos por los que navegar. Además, puede ser más o menos interactivo, requiriendo la participación del receptor para completar su sentido, pidiendo, por ejemplo, que el receptor asuma un determinado rol o punto de vista o elija entre distintas alternativas narrativas. En la mayor parte de los casos el reportaje multimedia tendrá como interface la página web y entonces la palabra escrita tendrá especial protagonismo. Pero el interface puede ser un vídeo interactivo, por naturaleza lineal, que se abre para desarrollar historias, situaciones o contextualizar a través de datos. $\mathrm{O}$ un 
vídeo inmersivo de $360^{\circ}$, que pretende trasladar la experiencia de 'estar allí'. En las estructuras más sencillas los elementos expresivos (palabra escrita, vídeo, audios, fotos, gráficos) se yuxtaponen, mientras que en las más complejas se interrelacionan más estrechamente, tendiendo a ofrecer una experiencia inmersiva sensorial semejante al del vídeo lineal.

El paradigma de reportaje multimedia aquí analizado es "Snow Fall: The Avalanche at Tunnel Creek", (The New York Times) que reconstruye un accidente ocurrido en una estación de esquí y en el que fallecieron tres experimentados montañeros. Su estructura narrativa profunda es básicamente cronológica, con avances y retrocesos en el tiempo. Esto se traduce en una estructura hipermedia sencilla: varios bloques narrativos de texto lineal a los que se accede desde una barra navegación superior, y que además están enlazados entre sí linealmente. Podemos recorrer (como en cualquier página web) estos textos lineales, que se van complementando con los distintos elementos multimedia, que unas veces apoyan el texto y otras veces lo amplían. La barra de navegación superior se completa con otros dos enlaces a las fotos del grupo y al mapa del lugar.

Figura 3. Reportaje multimedia The New York Times "Snow Fall".

\begin{tabular}{|l|l|}
\hline TUNNEL CREEK TO THE PEAK DESCENT BEgINS ELUR OF WHITE DISCONERY WORD SPREADS & MAP \\
Du Saugstad was mummified. She \\
was on her back, her head pointed \\
downhill. Her goggles were off. Her \\
nose ring had been ripped away. She \\
felt the crushing weight of snow on \\
her chest. She could not move her \\
legs. One boot still had a ski \\
attached to it. She could not lift her \\
head because it was locked into the \\
ice. \\
But she could see the sky. Her face \\
was covered only with loose snow. \\
Her hands, too, stuck out of the \\
snow, one still covered by a pink mitten.
\end{tabular}

\section{$\underline{\text { 3.2.3. Documentales audiovisuales interactivos }}$}

El documental es un género narrativo complejo que sólo se da en el cine, en la televisión y en algunos casos en la radio. ¿Dónde termina el reportaje y empieza el documental? No es fácil decirlo. El documental tiene una referencia más remota a la actualidad que el reportaje y es más perdurable. El documental tiene mayor ambición narrativa que el reportaje y se acerca más a la ficción. Pero a veces pierde la concentración narrativa del reportaje y tiene planteamientos más generales que concretos. 
En ocasiones el documental, como su nombre indica, documenta la realidad a través de visiones supuestamente neutras del mundo, pero otras veces lo que predomina es la voz subjetiva del autor. Los estudiosos no se ponen de acuerdo en el concepto. Así que la definición más laxa puede ser la de "obra audiovisual unitaria de larga duración y de no ficción”. Y en el caso del docuweb las posibilidades que se abren son casi infinitas.

Hemos dividido esta familia en tres subcategorías concretas, aunque si atendemos a la cantidad de ejemplos existentes podríamos elaborar una larga e interminable lista. Los ejemplos seleccionados representan tres subgéneros dentro de la clasificación: los documentales web, el docuweb vídeo interactivo y el docuweb vídeo participativo.

La cadena cultural franco-alemana ARTE, especializada en la realización de grandes documentales, ha desarrollado una línea denominada Webproductions. No se trata de adaptar un documental a la web, sino de producirlo de modo que al tiempo que se rueda para un documental en vídeo se vayan captando sobre el terreno otros contenidos multimedia que luego darán lugar al docuweb. Como documentales, su referencia a la actualidad es más o menos remota y su estructura narrativa es compleja. Como documental web hemos escogido "Baikal, el espejo de Rusia". El título ya nos da pistas del punto de vista: el mayor lago de agua dulce del mundo y la región que le rodea es el espejo de la gran e inabarcable Rusia. Como en todo reportaje una situación, historia o, en este caso, espacio geográfico nos sirve para conocer una realidad general.

Como docuweb interactivo hemos seleccionado "Honduras: en el reino del plomo", del LAB RTVE, que nos servirá, además, como caso de estudio y análisis del grupo de control. El título nos revela el punto de vista. En Honduras el soberano último no es el Estado sino la pistola humeante. Además de la página habitual del reportaje (donde, por ejemplo podemos acceder al guión del reportaje lineal), el trabajo se presenta en otros dos formatos, como WebDoc y como espacio interactivo en "La historia de Ebed".

La página de inicio es una animación de 47 segundos con música en la que se desgranan con imágenes alusivas las cifras de la violencia en Honduras. La barra superior de navegación da acceso al reportaje lineal en vídeo, a la "Historia de Ebed" y a "Extras". No es, por tanto, una barra de navegación de bloques narrativos, sino de los distintos formatos del reportaje.

Cuando finaliza la cabecera inmersiva, que nos introduce y actúa como un sumario, accedemos directamente a la versión docuweb. Se trata del reportaje lineal. En esta versión, sobre el vídeo del vídeo lineal -que arranca desde el principioencontramos una barra inferior que nos permite navegar por los distintos bloques narrativos. Bajo la barra de navegación aparecen unos puntos que abren ventanas a 'extras' (fotos, documentos, vídeos sin comentario complementarios, transcripciones completas de entrevistas).

En resumen, con este formato docuweb el reportaje se abre y su autor nos permite navegar por un conjunto de contenidos que complementan y contextualizar la narración. En este sentido, el punto de vista unificador y el hilo narrativo se dispersan. O, por decirlo de otro modo, el reportaje se convierte en docuweb. 
El tercer formato es el de una historia interactiva, la historia de Ebed, un muchacho asesinado. Para ello se crea un espacio interactivo, "La habitación de Ebed", a la que se accede desde la barra de navegación de formatos. Cuando entramos en la habitación de Ebed se destaca una pregunta “¿Qué le ocurrió a Ebed?”. En la ventana siguiente la respuesta nos la da su padre en un vídeo. Cada objeto de la habitación se convierte en una ventana emergente que da acceso a una ventana de contextualización (columna izquierda), que integra un texto y un vídeo sobre la vida de Ebed, las circunstancias de su muerte y la lucha de sus padres contra la impunidad. A diferencia de la versión docuweb en este espacio interactivo sí se mantiene el punto de vista y el hilo narrativo, por lo que puede considerarse que esta versión es un verdadero reportaje interactivo. En cuanto a la interactividad dialógica sólo está presente en la función de compartir en las redes sociales.

Figura 4. Documental interactivo ARTE "Baïkal, miroir de la Russie".

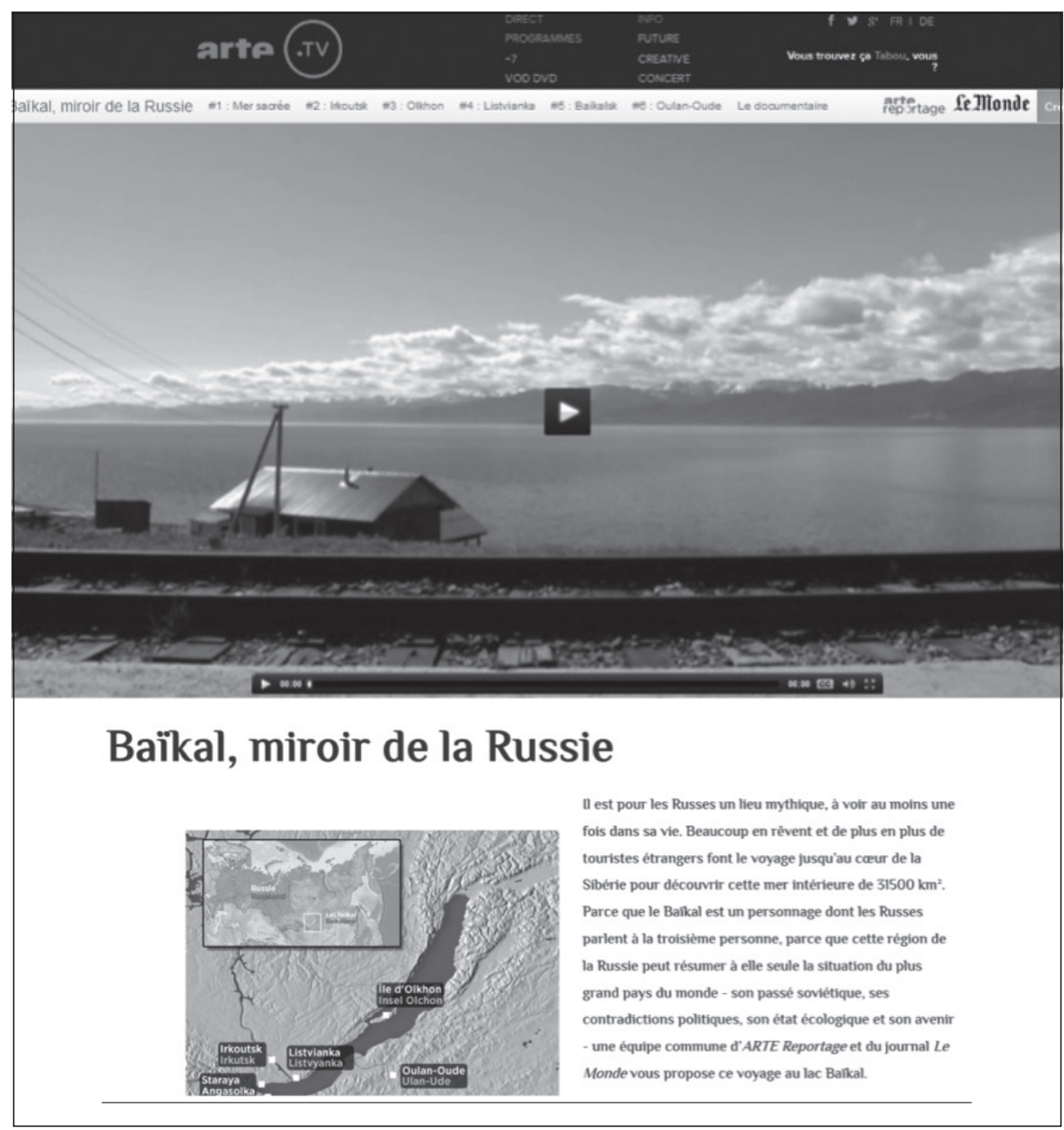


Figura 5. Documental interactivo RTVE "Honduras: en el Reino del Plomo".
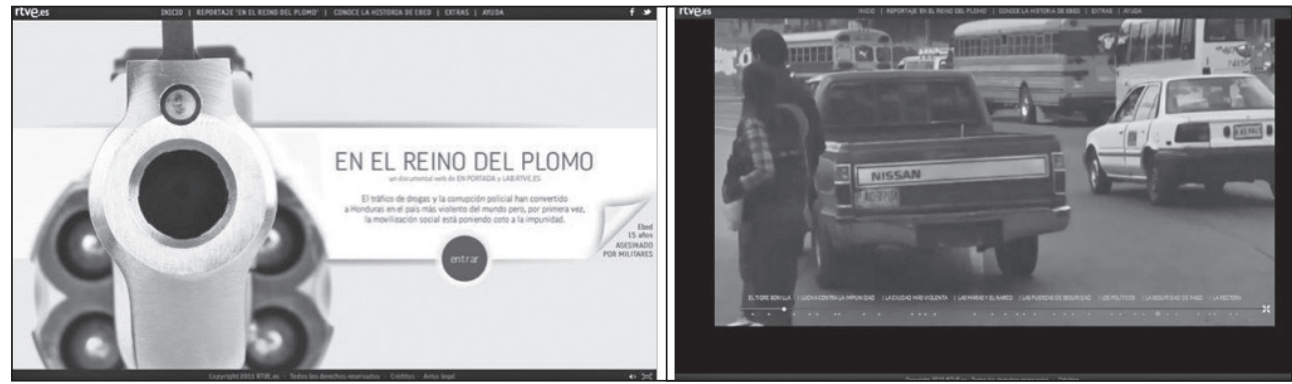

Para completar la clasificación hemos elegido como ejemplo de docuweb vídeo participativo el trabajo HonkyTonk Film, productora francesa especializada en docuweb, que declara que "internet es un lugar para desarrollar nuevos formatos narrativos, en los que la interactividad puede ayudar a construir grandes historias e implicar a nuestra audiencia como nunca hasta ahora". De acuerdo con esta premisa, sus productos buscan más una experiencia interactiva inmersiva que abrir el documental a otras informaciones y fuentes. Hemos seleccionado una de sus producciones más conocidas "Journey to the End of the Coal", el viaje a la región china donde miles de personas extraen un mineral esencial para el desarrollo de la economía china.

Una de sus características es el protagonismo de los sonidos para crear ambientes inmersivos. Al comenzar el vídeo una pantalla nos advierte del viaje que vamos a comenzar e implícitamente nos pide que adoptemos el rol de un reportero freelance en la región de Xhanxi. Adoptamos, como en un vídeojuego, el papel de reportero que viaja por la región., No hay comentario en off y todos los contenidos se muestran en bruto, como si acabaran de ser capturados. En algunos casos las entrevistas se muestran como un audio subtitulado, que vamos abriendo sobre una foto, acompañado por un bucle del sonido ambiente de la habitación y el omnipresente ulular del viento de fondo.

Así, uno tras otro, se van sucediendo destinos y bloques narrativos, que podemos saltar para volver a la ruta principal. "Journey to the end of the coal" es un documental web interactivo, que pretende implicar al receptor pidiéndole que asuma el papel de periodista, pero sus decisiones se limitan a la ruta a seguir y a ir descubriendo poco a poco las declaraciones de los entrevistados, a golpe de clic, como si realmente estuviera realizando las preguntas. Su estructura narrativa es, por supuesto, un viaje, una narrativa clásica en todo tipo de reportajes y documentales.

Un ejemplo más nos ayuda a comprender toda la intensidad y la capacidad de evolución y desarrollo del nuevo género documental interactivo, "FortMcMoney", producido por la National Film Board (NFB), organismo público del cine de Canadá, probablemente uno de los mayores productores mundiales de documentales.

"FortMcMoney" lleva al máximo la interacción en forma de participación y debate. Para ello se desarrolla en paralelo una serie documental de 6 capítulos de 1 hora y un vídeo-juego y, por tanto, supone una estrategia transmedia. El docujuego pone a debate las consecuencias medioambientales y sociales de un yacimiento petrolífero, 
y mediante la participación consigue dos objetivos a) un mejor conocimiento: para que la información se convierta en conocimiento es necesario interactuar con ella; b) un compromiso con el problema, primero en el espacio virtual del juego y, previsiblemente, proyectando ese compromiso a la esfera pública. Y un tercero, garantizar la fidelidad a la emisión lineal mediante el enganche al juego.

Figura 6. Documental interactivo HonkyTonk Films “Journey To The End Of Coal”.

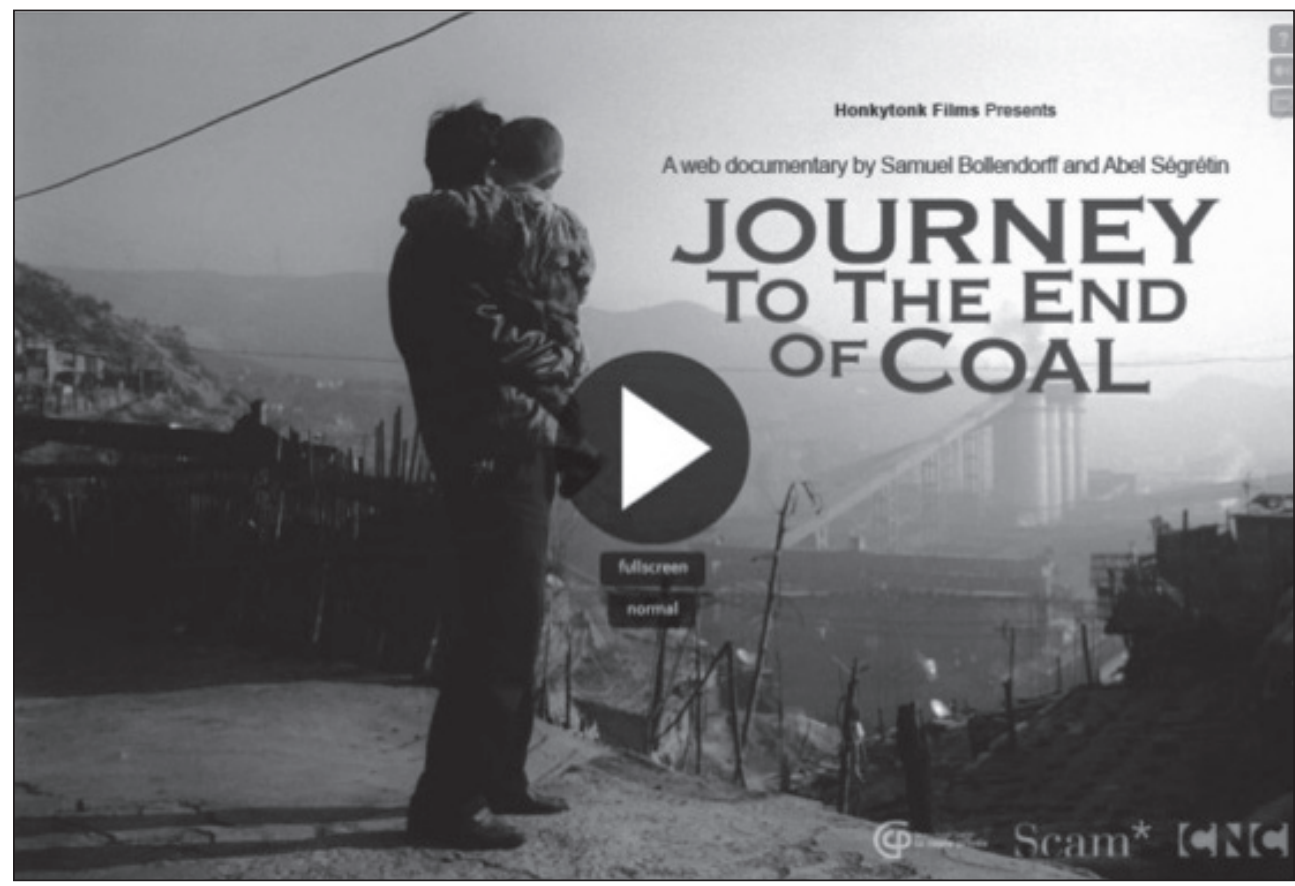

\section{Construcción de una metodología de producción adaptada al género}

Para realizar un docuweb deberemos seguir una serie de pasos, que en muchos casos reconoceremos como propios de cualquier actividad periodística.

\subsection{Investigación}

Como en cualquier trabajo periodístico en profundidad, en los reportajes multimedia hay que comenzar realizando una investigación todo lo exhaustiva que permita el tiempo de producción y los recursos a nuestro alcance. La realidad nos interpela, nos llama la atención y nos sugiere que hay algo que mostrar, explicar, desvelar. Investigando fuentes y recopilando documentación logramos dos objetivos. El primero, esencial, conocer y explicarnos a nosotros mismos todos aquellos aspectos que hacen interesante y relevante el asunto. Y el segundo, más práctico, buscar personas, historias, situaciones arquetípicas, localizarlas y contactarlas. Sin ellas, sin su accesibilidad y voluntad de cooperación, no habrá reportaje. 


\subsection{El foco y el punto de vista}

Conforme vamos investigando el reportaje se irá delimitando, de modo que antes de comenzar a producirlo, tendremos ya claro el foco, el punto de vista y probablemente el hilo narrativo. El foco consiste en centrarse en una de las dimensiones del asunto, sobre todo si se trata de una cuestión poliédrica. La crisis del periodismo puede abordarse desde muchas perspectivas y todas ellas pueden representarse en un especial, pero en un reportaje debemos de elegir una de esas dimensiones, por ejemplo, la relación de la formación de los periodistas con la crisis.

El punto de vista a menudo vendrá dado de antemano: ¿cómo nos aproximaremos a esta cuestión, desde qué rol? Por seguir con el ejemplo, ¿adoptaremos el papel del observador imparcial o nuestro punto de vista será el de los alumnos, el de los profesores, los profesionales? El punto de vista es la óptica con la que afrontamos el reportaje, pero puede estar ligado a una hipótesis que queremos verificar ("la formación inadecuada es una de las causas de la crisis de la profesión periodística"). Una hipótesis, que, como en una investigación científica, puede cumplirse o no. Lo que no puede ser es una tesis a defender. Para la defensa de tesis están los géneros de opinión.

Sin un foco claro y un punto de vista no puede comenzarse la producción, pero si somos honrados a lo largo de la producción podemos ir modificando, si no el foco, sí el punto de vista, adoptando otro que nos parezca más equilibrado o más eficaz para mostrar la realidad.

\subsection{La estructura y el hilo narrativo}

Puede que después de la etapa de investigación no sólo hayamos adoptado un foco y un punto de vista, sino que es bastante probable que atisbemos la estructura de nuestro relato; o puede que sólo después de la producción aparezca completamente clara. En cualquier caso, tenemos que ordenar todo nuestro contenido en bloques narrativos con coherencia y unidad interna y vincular unos con otros mediante un hilo narrativo.

En los reportajes lineales, la sucesión de bloques ya da una continuidad, pero ésta se ve reforzada si hay vínculos entre bloques, elementos (personajes, situaciones) que se repiten y dan mayor continuidad. En el caso del reportaje multimedia, cada bloque narrativo es mucho más independiente y por eso conviene que ese hilo narrativo unificador sea más explícito, que se muestre, que se visualice en el espacio de navegación.

\subsection{Espacio de navegación}

El espacio de navegación tiene que intentar representar el hilo narrativo. Si la estructura narrativa va a ser un viaje, el espacio de navegación puede ser un mapa, una carretera, una estación con distintos destinos u otra visualización semejante. Si el hilo narrativo es el descubrimiento de un espacio real (un edificio, un barrio) o simbólico (un cuadro), el espacio de navegación habrá de ser una imagen significativa (un mapa en relieve, una foto panorámica). Si la estructura es cronológica, el espacio 
de navegación será una línea de tiempo, de la que irán colgando los distintos elementos multimedia (una "re-mediación" de un relato lineal). Si la estructura se basa en historias personales, el espacio navegable deberá ser un conjunto de fotos de los personajes. Si la estructura narrativa es un proceso, el espacio navegable puede ser, por ejemplo, un diagrama de flujo o una red cuyos nodos sean imágenes significativas.

Para reforzar la navegabilidad, cada bloque narrativo deberá tener una barra de navegación con acceso al resto de los bloques y otras opciones como comentarios, debates, materiales extras etc. Y para aquellos que quieran hacer una lectura lineal, el autor ofrecerá al final de cada bloque el enlace al siguiente.

\subsection{El uso de los elementos mediáticos}

Cada bloque tendrá una estructura de planteamiento, nudo y desenlace, pero el reportaje requiere una introducción general, al modo del sumario de prensa o la presentación en estudio de la televisión. Esa presentación debe realizarse en la página de inicio. Una de las fórmulas más eficaces puede ser una página animada que nos muestre los datos esenciales, las preguntas del reportaje, el punto de vista, y que vaya acompañada por un sonido que cree un ambiente que nos acompañe a lo largo de todo el reportaje. Esta página introductoria -que podrá interrumpirse en cualquier momento- dará paso al espacio navegable a partir del cual el receptor irá haciendo su recorrido por los distintos bloques temáticos y construyendo, en consecuencia, su propia mensaje.

Si el texto va a ser el elemento expresivo protagonista debemos tener en cuenta que los media de carácter inmersivo (vídeos, animaciones, juegos) deben estar al principio o al final de cada bloque narrativo, para no interrumpir la lectura. El mensaje textual irá apoyado por fotos (galerías mejor al final o en una barra lateral) y fragmentos de vídeo breves: declaraciones que aportan el lenguaje gestual y la presencia del personaje, situaciones que demuestren de lo que se habla. Las entrevistas completas en vídeo o audio pueden ofrecerse en una página de extras, en una columna lateral o al final del respectivo bloque narrativo.

En el caso de un reportaje basado en el vídeo, la solución más sencilla es ofrecer información complementaria al comienzo o al final de cada bloque narrativo, mediante recuadros de imágenes o texto, o el caso de contar con alguna herramienta de interactividad, a través de ventanas emergentes que el receptor pueda abrir durante el visionado del vídeo.

\subsection{Interactividad}

Otro de los elementos a decidir es el grado de interactividad. La interactividad selectiva se logra a través de espacios y barra de navegación. Si el vídeo es el media dominante no debe agobiarse al receptor obligándole a tomar uno u otro sendero, en un jardín en el que los caminos se bifurcan continuamente.

La interactividad narrativa, más propia de la ficción, se logra dando al receptor la capacidad de elegir entre varios desarrollos posibles. La interactividad participativa se puede conseguir pidiendo al receptor que asuma un determinado rol o punto de vista, que explore determinadas situaciones o personajes, que efectúe determinadas 
simulaciones a partir de datos... Se trata de concienciar, de promover comportamientos respecto a la cuestión, en definitiva, de que el receptor convierta la información en conocimiento y adopte una posición respecto a la cuestión.

Lo que nunca debe faltar es la interactividad dialógica: dar la opción de debatir sobre el asunto mostrado. Además de una página general de debate, a la que se llegue desde una barra de navegación general, puede ser apropiado -dependiendo del tipo de reportaje, casi obligado en los de carácter argumentativo- plantear preguntas o cuestiones de debate al final de cada bloque narrativo. Otra solución sencilla es añadir una encuesta situada en una columna lateral.

\subsection{Realización}

Para elaborar un reportaje multimedia tenemos que acopiar contenidos en distintos media. Lo más útil puede ser realizar toda la captura de información con una cámara de vídeo. Del vídeo puede extraerse transcripciones, pero también fragmentos de declaraciones o situaciones. Sería muy conveniente hacer al mismo tiempo fotos, pero desde el vídeo pueden capturarse instantáneas. Si nuestro reportaje se va a publicar en la web la definición del vídeo puede no ser lo más importante, pero sí la calidad narrativa de la grabación (encuadres, movimientos de cámara). No obstante, hoy es prácticamente obligado producir en HD y permitir al receptor escoger la definición o adaptarla al dispositivo (diseño responsive).

Un buen reportaje con un alto grado de interacción requiere probablemente una herramienta de producción específica. Pero un reportaje multimedia, limitado a una interactividad selectiva y dialógica y con el texto como elemento expresivo protagonista, se puede elaborar en plataformas gratuitas, como un blog, una página creada en plataformas como wordpress.org o joomla y de forma muy sencilla con wix.com, que permite un diseño muy flexible y tiene gran facilidad para incrustar elementos mediáticos o crear módulos con ellos. No faltan herramientas de vídeo interactivo, pero muy limitadas en sus versiones gratuitas.

\section{Aceptación y adaptación. Un caso de estudio: "Honduras: en el reino del plomo"}

Para completar esta investigación hemos utilizado uno de los docuweb analizados, exponiéndolo a un grupo de control. El docuweb utilizado es "Honduras: en el reino del plomo", de RTVE. Nos ocupamos en este apartado de las impresiones recogidas y conclusiones obtenidas en nuestro grupo de control de dos formas distintas: a través de una reunión de focus group y, por otra parte, mediante una encuesta entre estudiantes del grado de Periodismo de la UCM para recoger de forma normalizada su impresiones sobre el visionado de las tres versiones del documental.

Se ha seleccionado un grupo semicualificado con el fin de dar una respuesta cualitativa a la investigación, sin despreciar los datos ofrecidos que, extrapolados gracias al diseño de la encuesta que incluye preguntas de control o verificación, ofrecen una información muy valiosa respecto al público general de este tipo de género ${ }^{4}$. El

\footnotetext{
${ }_{4}$ Para consultar la encuesta completa: https://docs.google.com/forms/d/18KcrgbP87vSV7euDzw0xq L4UsTqqu0sjSPeDxc6pvMc/edit?ts=576d0a34\#
} 
grupo muestra cierto desconocimiento de este tipo de género en la red. Se visiona esporádicamente y accede a través del ordenador, y no a través de otros dispositivos móviles (smartphones 4\%; tabletas 9\%).

El fondo del mensaje, la violencia en Honduras, muestra una realidad que por regla general es desconocida por el público, ya que normalmente se identifica ese nivel de violencia en Latinoamérica con otros países. El ritmo narrativo se ve entorpecido a veces por la navegación en la página, de forma que el espectador puede tender a desconectar en ciertos momentos de la historia que narra. El mensaje llega y es inteligible para los participantes y se desarrolla en profundidad a través de los testimonios y descripción de los personajes protagonistas. Todo ello es captado por el espectador sin dificultad. La mayoría entiende también (70\%) que la visión otorgada es subjetiva, es decir, la interactividad puede llevar a construir un mensaje más ambiguo en ese sentido.

En la versión interactiva el grupo detecta falta de cohesión en la información a la hora de seguir la historia. El valor más destacado es la presentación animada. Así se comprende cómo la mayoría de los docuweb introducen sus productos con una presentación inmersiva que retiene el tiempo suficiente para investigar el resto del material propuesto. La navegación es sencilla y no se encuentran dificultades técnicas que impidan la lectura/visionado del producto. Además, aporta una cantidad mayor de información con la ventaja de poder seleccionarla (66\% de los encuestados).

El nivel de satisfacción no va más allá de un notable, lo que sorprende dadas las características del producto (novedad, interactividad y aportación de gran cantidad de información). Tan sólo el 23\% se considera muy satisfecho con la experiencia. En lo que respecta a la parte interactiva, agradece la ampliación de la información que ayuda a contextualizar mejor las historias. A pesar de ello, la parte más interactiva del docuweb, "La habitación de Ebed", no consigue atraer ni interesar en general, considerando que aunque la idea es buena no está bien desarrollada. La mayor satisfacción con el docuweb frente al documental lineal no es excesiva. Los receptores los perciben como productos distintos. El grupo considera que el formato de documental televisivo se acerca más a la información, y su versión docuweb es más entretenimiento.

Basándonos en la encuesta podemos decir que se da una aceptación más que moderada de este nuevo género periodístico en la red. Sin embargo, hay todavía mucho desconocimiento sobre la existencia del producto docuweb en sí. El consumidor de docuweb tiene un perfil de joven entre 18 y 30 años y es usuario habitual de las redes sociales. Se detecta una buena acogida del género, aunque con críticas al docuweb concreto que se trata aquí.

\section{Conclusiones}

Después de realizar una categorización de los productos en los que se suman elementos multimedia, interactividad y narración elaborada, aunque parezca una contradicción, pensamos que toda clasificación rígida está abocada al fracaso, dado el carácter híbrido de estos contenidos. Lo esencial es discernir sus funciones narrativas: más abiertas o más cerradas, más diegéticas o más miméticas, más concentradas o dispersas. No obstante, creemos que dentro del docuweb pueden distinguirse las categorías 
del especial (visión globalizadora, narración dispersa en la que se recogen narraciones provenientes de muchas fuentes y distintos géneros), el reportaje interactivo (narración diegética, multimedia, centrada en la actualidad más inmediata y con una interactividad narrativa limitada) y el documental interactivo (narración mimética, multimedia, más despegada de la actualidad y con una interactividad narrativa rica).

A la hora de establecer una metodología de producción lo primero es determinar el tipo de producto que se pretende crear, tomando básicamente como referencia las tres categorías de docuweb anteriormente indicadas. Y a partir de ahí establecer una estrategia narrativa, una estrategia de navegación -lo que implica el diseño de un espacio navegable y una estructura narrativa-, una estrategia multimedia y una estrategia de interacción.

Finalmente, el estudio de caso nos ha mostrado que incluso una audiencia a la que se podría presuponer una actitud favorable sólo encuentra un grado limitado de satisfacción. Por supuesto, esta conclusión puede estar vinculada a la propia factura del producto escogido, pero hay otro hallazgo que parece más general: la falta de constancia para realizar una lectura o visionado de todos los materiales propuestos, los sujetos estudiados mostraron una disposición a no consumir ni siquiera tanto tiempo como el que habrían dedicado al visionado del documental clásico lineal. Creemos que deben desarrollarse nuevas investigaciones desde la perspectiva de los estudios de recepción.

\section{Referencias bibliográficas}

ASTON, J., GAUDENZI, S. (2012). Studies in documentary film interactive documentary : setting the field. Studies in documentary Film, 6(2), 125-39.

BOCK, M. A. (2015). Showing versus telling: comparing video narratives on newspaper and television websites video. Journalism, 11, 1-25.

CISCO (2016). June Middle East Cisco Visual Networking Index : Forecast and Methodology , 2013 - 2018. http://www.cisco.com/en/US/solutions/collateral/ ns341/ns525/ns537/ns705/ns827/white_paper_c11-481360_ns827_Networking_ Solutions_White_Paper.html

DÍAZ NOCI, J. (2009). Multimedia y modalidades de lectura: una aproximación al estado de la cuestión. Comunicar, 16(33), 213-19.

DOMÍNGUEZ,E.(2010).Eldocumentalcomovivenciadigital.La Vanguardia,21/12/10. http://blogs.lavanguardia.com/elcuartobit/el-documental-como-vivencia-digital.

FERNANDEZ JARA, L., ROEL, M. (2014). El documental periodístico: propuesta de caracterización a través del análisis de documentos tv y en portada. Estudios Sobre el Mensaje Periodistico, 20(2), 677-94.

GIFREU, A. (2011). El documental multimedia interactivo como discurso de la no ficción interactiva. por una propuesta de definición y categorización del nuevo 
género emergente. Hipertext.net, 9. http://www.upf.edu/hipertextnet/numero-9/ documental-multimedia.html

GIFREU, A. (2013). El documental interactivo. Evolución, caracterización y perspectivas de desarrollo. Barcelona: UOC.

GOSCIOLA, V., CAMPALANS, C (2013). Géneros de narrativa transmedia y periodismo. En Denis Renó, Carolina Campalans, Sandra Ruiz, Vicente Gosciola, Elizabeth Gonçalves, Periodismo transmedia: miradas múltiples (pp. 35.52). Barcelona: UOC, Rosario: Universidad de Rosario.

JENKINS, H. (2008). Convergence culture, where old and new media collide. Nueva York: NYU.

LARRONDO, A. (2010). Propuesta metodológica para una aproximación empírica a los géneros ciberperiodísticos. Zer, 15(28), 157-74. http:/www.ehu.es/zer/ es/hemeroteca/articulo/Propuesta-metodolgica-para-una-aproximacin-emprica-a-los-gneros-ciberperiodsticos/437\nhttp://europa.sim.ucm.es/compludoc/ AA? articuloId $=770434$

LARRONDO, A. (2011). La metamorfosis del reportaje en el ciberperiodismo: concepto y caracterización de un nuevo modelo narrativo. Comunicacion y Sociedad, 22(2), 59-88.

LEÓN, B., NEGREDO, S. (2014). Documental web. una nueva página para el viejo sueño interactivo. Telos, 96, 1-10. http://sociedadinformacion.fundacion.telefonica.com/DYC/TELOS/LTIMONMERO/DetalleArtculo_96TELOS_DOSSIER4/ seccion $=1288 \&$ idioma $=$ es_ES\&id=2013102313530001\&activo=6.do

LÓPEZ GARCÍA, G, (2003). Géneros interpretativos: el reportaje y la crónica. En Javier Díaz Noci, Ramón Salaverría (coords.), Manual de redacción ciberperiodística (pp. 448-94). Barcelona: Ariel, ,.

MARRENO, L. (2008). El reportaje multimedia como género del periodismo digital actual. acercamiento a sus rasgos formales y de contenido. Revista Latina de Comunicación Social, 63, 1-21.

MARTA, C. (2012). Reportaje y documental: de géneros televisivos a cibergéneros.

MAYORAL, J., EDO, C. (2014). Evolución de la producción audiovisual en cinco cibermedios españoles. Fonseca, Journal of Communication, 9, 233-62.

MEADOWS, M. S. (2003). Pause \& Effect: The art of interactive narrative. Indianapolis: New Readers.

O'FLYNN, S. (2012). Studies in documentary film documentary's metamorphic form : participatory and beyond documentary' s metamorphic form: webdoc, interactive. Studies in Documentary Film, 6(2), 141-57.

SCOLARI, C. A. (2009). Transmedia storytelling: implicit consumers, narrative worlds, and branding in contemporary media production. International Journal of Communication, 3, 21. http://ijoc.org/index.php/ijoc/article/view/477

VÁZQUEZ HERRERO, J., LÓPEZ GARCÍA, X. (2015). Reportaje interactivo: un género periodístico para el medio digital. En De los medios a los metamedios. Actas I Simposio de la Red Internacional de Investigación de Gestión de la Comunicación, https://delosmediosalosmetamedios.files.wordpress.com/2016/03/7reportaje-interactivo-un-gecc81 nero-periodicc81stico-para-el-medio-digital.pdf 


\section{Docuwebs}

ABC "El caso Malaya". En http://www.abc.es/especiales/caso-malaya [consultado el 21/04/2014].

ARTE "Baikal, miroir de la Russie". En http://php4.arte.tv/info/2013/20130629baikal/baikal_fr.html\#home [consultado el 11/11/2014].

El Mundo "Elecciones Generales 2011". En http://www.elmundo.es/elecciones/ elecciones-generales/ [consultado el 11/11/2014].

El País “Goya 2014”. En http://elpais.com/especiales/premios-goya/ [consultado el 11/11/2014].

HonkyTonk Film "Journey to the End of the Coal". En www.honkytonk.fr/index. $\mathrm{php} / \mathrm{webdoc/}$ [consultado el 11/11/2014].

NFB "Fort McMoney". En http://fortmcmoney.com/en/\#/fortmcmoney [consultado el 11/11/2014].

RTVE "Honduras: en el Reino del Plomo" (En Portada). En http://lab.rtve.es/en-elreino-del-plomo/documental.html [consultado el 11/11/2014].

RTVE “La sonrisa de Mandela”. En http://lab.rtve.es/nelson-mandela/la-sonrisa-demandela/ [consultado el 11/11/2014].

RTVE "Loteria de Navidad 2013”. En http://www.rtve.es/sorteos/loteria-navidad/ [consultado el 11/11/2014].

The Economist "The Long Walk of Mandela". En http://www.mandelaswalk.com/ (consultado el 11/11/2014) [consultado el 11/11/2014].

The New York Times "Snow Fall: The Avalanche at Tunnel Creek". En http:// www.nytimes.com/projects/2012/snow-fall/\#/?part=tunnel-creek [consultado el $11 / 11 / 2014]$. 